\title{
Impact of free newborn care service package on out of pocket expenditure- evidence from a multicentric study in Nepal
}

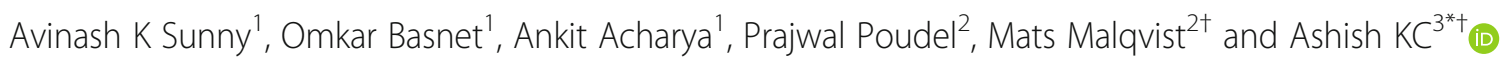

\begin{abstract}
Background: Sustainable Development Goal (SDG) aspires to improve universal health coverage through reduction of Out of Pocket Expenditure (OOPE) and improving the quality of care. In the last two decades, there have been several efforts to reduce the OOPE for maternal and newborn care. In this paper, we evaluate the change in the OOPE for treatment of sick newborn at hospital before and after implementation of a free newborn care (FNC) program in hospitals of Nepal.

Methods: Ministry of Health and Population implemented a free newborn care program which reimbursed the cost of treatment for all sick newborns admitted in public hospitals in Nepal from November 2017. We conducted this pre-post quasi-experimental study with four months of pre-implementation and 12 months of postimplementation of the program in 12 hospitals of Nepal. Logistic regression analysis was conducted for categorical variables and Mann-Whitney test was applied for continuous variables to determine statistically significant differences between pre- and post- intervention period.

Results: A total of 353 sick newborns were admitted into these hospitals before implementation of the FNC program while 1122 sick newborns were admitted after the implementation. Before implementation, 17\% of mothers paid for sick newborn care while after implementation $15.3 \%$ mothers ( $p$-value $=0.59$ ) paid for care. The OOPE for treatment of sick newborn at hospital before implementation was Mean \pm SD: US dollar $14.3+12.1$ and after implementation was Mean \pm SD: USD $13.0 \pm 9.6(p$-value $=0.71)$. There were no significant differences in neonatal morbidity after the implementation of the FNC program. The stay in a hospital bed (in days) decreased after the implementation of FNC program ( $p$-value $<0.001$ ) while the cost for medicine increased $(p$-value $=0.02)$. The duration of hospital stay (in days) of sick newborns significantly decreased for Hypoxic Ischemic Encephalopathy $(\mathrm{HIE})(p$-value $=0.04)$ and neonatal sepsis $(p$-value $<0.001)$ after the FNC program was implemented.
\end{abstract}

(Continued on next page)

\footnotetext{
*Correspondence: ashish.k.c@kbh.uu.se

Mats Malqvist and Ashish KC are senior authors

${ }^{3}$ Department of Women's and Children's Health, Uppsala University, Dag

Hammarskjölds väg 14B, Uppsala, Sweden

Full list of author information is available at the end of the article
}

(C) The Author(s). 2021 Open Access This article is licensed under a Creative Commons Attribution 4.0 International License, which permits use, sharing, adaptation, distribution and reproduction in any medium or format, as long as you give appropriate credit to the original author(s) and the source, provide a link to the Creative Commons licence, and indicate if changes were made. The images or other third party material in this article are included in the article's Creative Commons licence, unless indicated otherwise in a credit line to the material. If material is not included in the article's Creative Commons licence and your intended use is not permitted by statutory regulation or exceeds the permitted use, you will need to obtain permission directly from the copyright holder. To view a copy of this licence, visit http://creativecommons.org/licenses/by/4.0/ The Creative Commons Public Domain Dedication waiver (http://creativecommons.org/publicdomain/zero/1.0/) applies to the data made available in this article, unless otherwise stated in a credit line to the data. 
(Continued from previous page)

Conclusions: We found no change in the OOPE for sick newborn care following implementation of the FNC Program. There is a need to revisit the FNC program by the type of morbidity and duration of stay. Further studies will be required to explore the health system adequacy to implement such programs in hospitals of Nepal.

Trial registration: ISRCTN- 30829654, Registered on May 02, 2017.

Keywords: Free Newborn Care Program, Impact, Out of Pocket Expenditure, Sick newborn, Nepal

\section{Background}

One of the core principles of the Sustainable Development Goals (SDGs) is to leave no one behind in terms of accessing care [1]. This core principle provides impetus for universal health coverage (UHC)[2]. There has been a surge to introduce health financing schemes targeted for mothers and children in low-income settings where the financial burden is a major determinant to access care at health facilities[3]. In essence of these efforts for reducing the financial burden of travel and treatment expenses, a Maternity Incentive Scheme (MIS) was implemented in Nepal in 2005 which was further expanded to provide free delivery services in 2009[4].

One of the key barriers towards the achievement of $\mathrm{UHC}$ is out of pocket expenditure (OOPE), defined as direct payment for the cost of care[5,6]. In order to mitigate such barriers to ensure UHC, there is a need to design effective interventions along with evidences and a financing strategy[7]. This is important as OOPE in many developing countries accounts for almost threequarters or more of total expenditure on health[8-10]. Examples of financing schemes range from providing cash payments to mothers and families at the time of admission, voucher schemes during antenatal care, and reimbursing the cost of care at the health facilities[11-13]. Despite these efforts and investments by the global community to address concerns over high OOPE, the inequity gap for utilizing health facilities during childbirth has further widened in the last decade[14].

OOPE for sick newborn care can cause households to suffer catastrophic expenditures which can lead them into poverty[15]. Women from low socio-economic backgrounds who have to make direct payment for obstetric and neonatal complications are more vulnerable to catastrophic expenditures[16][17].

With increase in utilization of maternal and newborn care in last 20 years and with more than $60 \%$ of deliveries now taking place in health facility, there is a need for specialized care for sick newborn in Nepal[18]. However, sick newborns who require specialized care and require longer duration of stay have implication of cost of care, usually overburdening parents for out of pocket expenditure $[19,20]$. As a result, use of specialized care is limited due to the unbearable financial expenses required[21, 22]. To address this barrier, the Government of Nepal introduced a free newborn care (FNC) service program in public hospitals in 2016[23]. The scheme aims to align with pre-existing free health care scheme to provide subsidy for drugs, laboratory diagnosis and bed charges [23]. The FNC program is a financing scheme to provide subsidy for treatment for all sick newborns. The financing scheme aims to take no cost for treatment of sick newborn admitted in the hospital (admission charge, bed charge, laboratory diagnosis, drug and doctor fee).

As there is limited evidence on the impact of the free newborn care program on OOPE, this study was conducted to assess the impact of the FNC program introduced in Nepal by comparing OOPE of sick newborn treatment in hospital (admission charge, drugs, laboratory diagnosis, doctors fee and bed charge) before and after implementation in 12 public hospitals.

\section{Method}

A pre-post quasi-experimental study, nested within a large stepped-wedged randomized control trial to evaluate the effectiveness of quality improvement interventions in 12 public hospitals of Nepal[24], was conducted among all births occurring in these hospitals between the 1 July 2017 and the 17 October 2018 with first four months as pre-intervention period and remaining twelve months as intervention period.

Based on the readiness of health facilities, newborn care in health facilities is classified into three levels- primary or basic neonatal level care at primary health care centers (level 1), secondary level care at special newborn care unit (SNCU) (level 2) and tertiary level care at neonatal intensive care unit (NICU) (level 3) [25]. As of November 2017, the FNC service package was implemented in all the public hospitals across the country. Department of Health Services, Child Health Division reimbursed the costs to public hospitals which provide free newborn care package based on the level of newborn care. The amount of reimbursement to each hospital per sick newborn is given based on the package of free newborn implemented (Table 1). The hospital which implement package A receive 9.6 USD per sick newborn admitted. The package A consists of basic sick newborn care. The hospital which implement package $B$ receive 19.2 USD per sick newborn admitted. The package $\mathrm{B}$ consists of specialized newborn care. The hospital which implement package $C$ receive 48.0 USD per sick newborn admitted. The package $C$ consists of neonatal intensive care. 
Table 1 Free Newborn Care Service Program

\begin{tabular}{|c|c|c|c|}
\hline Package & Services & $\begin{array}{l}\text { Level of newborn } \\
\text { care }\end{array}$ & $\begin{array}{l}\text { Reimbursement United States Dollar per } \\
\text { sick newborn admitted }\end{array}$ \\
\hline "A" & $\begin{array}{l}\text { - Medicines- Antibiotics, dextrose, IV Canula, etc. } \\
\text { - Laboratory services including blood testing } \\
\text { - Oxygen Supply by hood box /nasal prong } \\
\text { - X-ray / USG }\end{array}$ & $\begin{array}{l}\text { Basic Sick Newborn } \\
\text { Care }\end{array}$ & 9.6 \\
\hline "B" & $\begin{array}{l}\text { - Photo therapy } \\
\text { - Laboratory Services- Blood culture, RFT (Sodium, Potassium, Urea } \\
\text { creatinine), Serum calcium } \\
\text { - Lumbar Puncture and CSF Analysis } \\
\text { - Medicine- Dopamine, Dobutamine, Phenobarbitone, Phenytoin, } \\
\text { Midazolam, calcium Gluconate, Aminophylene } \\
\text { - Bubble CPAP (Continuous Positive Airway Pressure) }\end{array}$ & $\begin{array}{l}\text { Specialised Sick } \\
\text { Newborn Care }\end{array}$ & 19.2 \\
\hline "C" & $\begin{array}{l}\text { - NICU Admission (Must) } \\
\text { - NICU bedside Ultrasonography (USG) } \\
\text { - NICU bedside Portable X-Ray } \\
\text { - Lab: ABG, Magnesium, Chloride, Serum Osmolarity, Urine Specific } \\
\text { Gravity, Urine Electrolyte } \\
\text { - Double Volume Exchange Transfusion, Blood transfusion } \\
\text { - Medicine: Caffeine } \\
\text { - Mechanical Ventilation }\end{array}$ & $\begin{array}{l}\text { Neonatal Intensive } \\
\text { Care Service }\end{array}$ & 48.0 \\
\hline
\end{tabular}

\section{Setting}

Study was conducted in the twelve government-funded hospitals where referral care for mothers and newborns are provided. These hospitals varied in terms of the utilization of care, geographical location, religious ethnicity, language. Four of the hospitals had more than 8,000 deliveries a year, four hospitals 3,000-8000 deliveries a

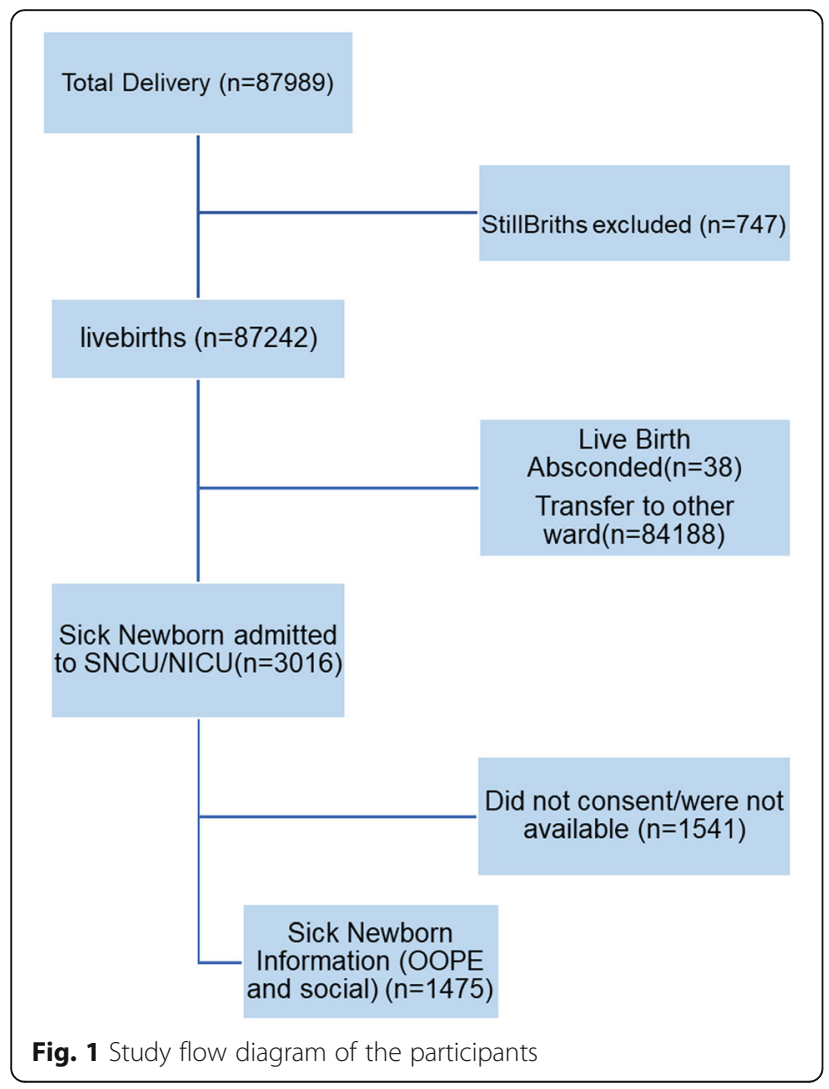

year, and the remaining four hospitals had 1,000-3000 deliveries a year. The low volume hospitals (Bardiya, Pyuthan, Nuwakot, and Nawalparasi) did not have specialized care services for sick newborn. The high-volume hospitals (Koshi Zonal, Bharatpur, Lumbini Zonal, and Bheri Zonal) and medium-volume hospitals (Western Regional, Rapti Sub-Regional, Mid-Western Regional, and Seti Zonal) provided specialized newborn care services. The SNCUs s were led by the pediatricians while in low volume hospitals, sick newborns were managed by medical doctors at the pediatric unit. In the sick newborn care units, management of sick newborns was done by medical doctors with 24 hours care from nursing staff.

\section{Participants}

All babies delivered in the study period who were admitted for sick newborn care were included in this study. Births with missing data on the cost of care were excluded from the analyses.

\section{Variables and outcomes}

Out-of-pocket expenditure (OOPE) was defined as a fee made by an individual for a consultation with a health professional, an investigation or procedure, medicines, supplies and laboratory tests.

Neonatal morbidity: Sick newborns were classified having any of the following diagnoses[26]:

- Hypoxic Ischemic Encephalopathy (HIE): Syndrome of abnormal neurological behavior in the neonate, which is frequently associated with multi-system dysfunction and follows severe injury before or during delivery. 
Table 2 Background Characteristics of the Sick Newborn

\begin{tabular}{|c|c|c|c|c|}
\hline Variables & Before FNC $(n=353)$ & After FNC $(n=1122)$ & $\begin{array}{l}\text { Total } \\
(n=1475)\end{array}$ & $p$-value \\
\hline Maternal age & $23.65 \pm 4.01$ & $24.09 \pm 4.49$ & $23.98 \pm 4.38$ & \\
\hline $20-35$ & $254(72.0 \%)$ & $818(72.9 \%)$ & $1072(72.7 \%)$ & \\
\hline$<20$ & $96(27.2 \%)$ & $285(25.4 \%)$ & $381(25.8 \%)$ & 0.56 \\
\hline$\geq 35$ & $3(0.8 \%)$ & $19(1.7 \%)$ & $22(1.5 \%)$ & 0.28 \\
\hline \multicolumn{5}{|l|}{ Education } \\
\hline Secondary and above & $266(75.4 \%)$ & $717(63.9 \%)$ & $983(66.6 \%)$ & \\
\hline Illiterate & $19(5.4 \%)$ & $94(8.4 \%)$ & $113(7.7 \%)$ & 0.02 \\
\hline Literate & $31(8.8 \%)$ & $137(12.2 \%)$ & $168(11.4 \%)$ & 0.02 \\
\hline Basic education & $37(10.5 \%)$ & $174(15.5 \%)$ & $211(14.3 \%)$ & 0.004 \\
\hline \multicolumn{5}{|l|}{ Ethnicity } \\
\hline Dalit & $47(13.3 \%)$ & $174(15.5 \%)$ & $221(15.0 \%)$ & 0.06 \\
\hline Janjati & $102(28.9 \%)$ & $308(27.5 \%)$ & $410(27.8 \%)$ & 0.18 \\
\hline Madhesi & $15(4.2 \%)$ & $94(8.4 \%)$ & 109 (7.4\%) & 0.003 \\
\hline Muslim & $6(1.7 \%)$ & $38(3.4 \%)$ & $44(3.0 \%)$ & 0.03 \\
\hline Chhetri/Brahmin & $160(45.3 \%)$ & $460(41.0 \%)$ & $620(42.0 \%)$ & 0.24 \\
\hline Others & $23(6.5 \%)$ & $48(4.3 \%)$ & $71(4.8 \%)$ & \\
\hline \multicolumn{5}{|l|}{ Parity (previous birth) } \\
\hline Primipara (1) & $126(35.7 \%)$ & $422(37.6 \%)$ & $548(37.2 \%)$ & \\
\hline Nullipara (0) & $77(21.8 \%)$ & $347(30.9 \%)$ & $424(28.7 \%)$ & 0.07 \\
\hline Multipara (2-5) & $150(42.5 \%)$ & $353(31.5 \%)$ & $503(34.1 \%)$ & 0.01 \\
\hline \multicolumn{5}{|l|}{ Neonatal Morbidity } \\
\hline HIE & 89 (25.2\%) & $275(24.5 \%)$ & $364(24.7 \%)$ & 0.54 \\
\hline NNS & $114(32.3 \%)$ & $310(27.6 \%)$ & $424(28.7 \%)$ & 0.14 \\
\hline $\mathrm{HBL}$ & $11(3.1 \%)$ & $31(2.8 \%)$ & $42(2.8 \%)$ & 0.60 \\
\hline MAS & $21(5.9 \%)$ & $82(7.3 \%)$ & $103(7.0 \%)$ & 0.61 \\
\hline RDS & $6(1.7 \%)$ & $42(3.7 \%)$ & $48(3.3 \%)$ & 0.11 \\
\hline Others & $112(31.7 \%)$ & $382(34.0 \%)$ & $494(33.5 \%)$ & \\
\hline \multicolumn{5}{|l|}{ Birth Weight } \\
\hline $2500-4000$ & $241(68.3 \%)$ & $770(68.6 \%)$ & $1011(68.5 \%)$ & \\
\hline$<2500$ & $103(29.2 \%)$ & $334(29.8 \%)$ & $437(29.6 \%)$ & 0.91 \\
\hline$\geq 4000$ & $9(2.5 \%)$ & $18(1.6 \%)$ & $27(1.8 \%)$ & 0.26 \\
\hline \multicolumn{5}{|l|}{ Gestational Age } \\
\hline 37-42 weeks & $211(59.8 \%)$ & $680(60.6 \%)$ & 891 (60.4\%) & \\
\hline$<37$ weeks & $113(32.0 \%)$ & $383(34.1 \%)$ & $496(33.6 \%)$ & 0.71 \\
\hline$\geq 42$ weeks & $29(8.2 \%)$ & $59(5.3 \%)$ & $88(6.0 \%)$ & 0.06 \\
\hline
\end{tabular}

${ }^{*} \mathrm{COR}$ crude Odds Ratio

- Neonatal sepsis (NNS): Clinical signs of severe bacterial infection, with a blood culture positive for a pathogenic organism.

- Hyperbilirubinemia (HBL): Babies with total Serum Bilirubin (TSB) increasing by $>5 \mathrm{mg} / \mathrm{dl} /$ day or $0.5 \mathrm{mg} / \mathrm{dl} /$ hour, $\mathrm{TSB}>15 \mathrm{mg} / \mathrm{dl}$, conjugated serum bilirubin $>2 \mathrm{mg} / \mathrm{dl}$.
- Meconium aspiration syndrome (MAS): Breathing problems that a newborn baby may have when there are no other causes, and the baby has passed meconium (stool) into the amniotic fluid during labour or delivery.

- Respiratory Distress Syndrome (RDS): Neonate with signs of respiratory distress-cyanosis, tachypnoea 
Table 3 Duration of Stay in days by Neonatal morbidity

\begin{tabular}{|c|c|c|c|c|c|c|c|}
\hline \multirow{2}{*}{$\begin{array}{l}\text { Duration } \\
\text { of stay }\end{array}$} & \multirow{2}{*}{$\begin{array}{l}\mathrm{N} \\
(353)\end{array}$} & \multicolumn{2}{|c|}{ Before Free Newborn Care } & \multirow{2}{*}{$\begin{array}{l}\mathrm{N} \\
(1122)\end{array}$} & \multicolumn{2}{|c|}{ After Free Newborn Care } & \multirow[t]{2}{*}{$p$-value } \\
\hline & & Mean \pm SD & Median (IQR) & & Mean \pm SD & Median (IQR) & \\
\hline HIE & 88 & $3.48 \pm 3.86$ & $2.50(0-16)$ & 269 & $3.28 \pm 5.86$ & $2(0-38)$ & 0.04 \\
\hline NNS & 112 & $4.39 \pm 4.22$ & $4(0-31)$ & 306 & $3.71 \pm 5.91$ & $2(0-39)$ & $<0.001$ \\
\hline $\mathrm{HBL}$ & 11 & $5.27 \pm 5.15$ & $3(0-17)$ & 31 & $5.19 \pm 6.48$ & $4(0-35)$ & 0.88 \\
\hline MAS & 20 & $3.80 \pm 3.76$ & $3(0-16)$ & 82 & $3.60 \pm 6.08$ & $3(0-38)$ & 0.23 \\
\hline RDS & 6 & $11.67 \pm 12.70$ & $7(0-35)$ & 41 & $3.17 \pm 5.95$ & $2(0-36)$ & 0.09 \\
\hline Others & 112 & $4.53 \pm 5.43$ & $3(0-38)$ & 375 & $4.01 \pm 6.83$ & $2(0-38)$ & $<0.001$ \\
\hline
\end{tabular}

(>60/min, shallow, rapid), grunting (delayed expiration maintains Functional residual capacity), retraction (Subcostal, sub-sternal, intercostal), flaring (50\% airway resist in nose\& pharynx).

Others included low birth weight, shoulder dystocia, hypoglycemia, congenital malformation, etc.

\section{Data collection and management}

Data were collected through an independent data collection team established in all the hospitals. The data collectors extracted obstetric and neonatal information from from the maternity registers and medical records using an extraction form. Information of sociodemographic variables and and OOPE were collected by the data collectors at through semi-structured interviews with mothers before discharge. All filled up forms were then assessed by a data coordinator on completeness and accuracy at each hospital. Data were then entered into the data base by the data entry and management team using the Census and Survey Processing System (CSPro).

\section{Statistical analysis}

The cleaned data were imported into Statistical Package for Social Sciences (SPSS) version 23 for analysis. Descriptive statistics were presented with mean, standard deviation (SD), median, interquartile range (IQR), frequency and percentage. Logistic regression was used to compare background characteristics of the sick newborns and the Mann-Whitney test was applied for comparing the cost of care between the groups. MannWhitney $U$ test was used to compare the difference of OOPE between two different time periods and the OOPE might not have been normally distributed. Logistic regression was used to explore the association between sick newborns and expenditure for services received. P-value $<0.05$ was considered to be statistically significant. Missing data were excluded from the analyses.

\section{Ethical approval and consent}

Written informed consent was obtained from the mothers before inclusion in the study and confidentiality was maintained. The study was approved by Ethical Review Board of Nepal Health Research Council (reference number 26-2017).

\section{Results}

There was a total of 87,989 deliveries observed in the study period, out of which 87,242 were livebirths and 747 stillbirths. Among these livebirths, 3016 sick newborns were admitted into the special newborn care unit and neonatal intensive care unit. Out of these sick newborns we could obtain consent for out of pocket

Table 4 Association between those who paid for services before and after FNC implementation

\begin{tabular}{llllll}
\hline Variables & Before FNC $(\boldsymbol{n}=\mathbf{3 5 3})$ & After FNC $(\boldsymbol{n = 1 1 2 2 )}$ & $\begin{array}{l}\text { Total } \\
(\boldsymbol{n}=\mathbf{1 4 7 5})\end{array}$ & $\begin{array}{l}\text { cOR } \\
(\mathbf{9 5} \% \mathrm{Cl})\end{array}$ & $\begin{array}{l}\text { aOR } \\
\mathbf{( 9 5 \%} \text { C.I.) }\end{array}$ \\
\hline Paid for services & & & & & \\
No & $293(83.0 \%)$ & $950(84.7 \%)$ & $1243(84.3 \%)$ & Reference & Reference \\
Yes & $60(17 \%)$ & $172(15.3 \%)$ & $232(15.7 \%)$ & $1.13(0.82-1.56)$ & $0.91(0.65-1.28)$ \\
\hline
\end{tabular}

Cox and Snell pseudo $R$-squared: 0.04; Nagelkerke pseudo $R$-squared: 0.06;

Hosmer and Lemeshow Test: $\mathrm{x}^{2}(8)=5.35, p=0.72$

adjusted for maternal age, education, ethnicity, parity, neonatal morbidity, birth weight and gestational age 
Table $\mathbf{5}$ OOPE by type of services for care among those who paid for the services

\begin{tabular}{|c|c|c|c|}
\hline & Before FNC (N-60) & After FNC (N-172) & $p$-value * \\
\hline \multicolumn{4}{|c|}{ Admission charge } \\
\hline Mean \pm SD & $0.1 \pm 0.5$ & $0.14 \pm 1.3$ & 0.21 \\
\hline Median (IQR) & $0(0-3.8)$ & $0(0-14.4)$ & \\
\hline \multicolumn{4}{|l|}{ Bed charge } \\
\hline Mean \pm SD & $6.4 \pm 6.5$ & $3.1 \pm 5.3$ & $<0.001$ \\
\hline Median (IQR) & $450(0-24.0)$ & $0(0-24.0)$ & \\
\hline \multicolumn{4}{|c|}{ Laboratory diagnosis } \\
\hline Mean \pm SD & $2.5 \pm 3.2$ & $3.4 \pm 4.2$ & 0.55 \\
\hline Median (IQR) & $2.4(0-13.4)$ & $2.4(0-15.5)$ & \\
\hline \multicolumn{4}{|l|}{ Doctor fees } \\
\hline Mean \pm SD & $1.9 \pm 0.1$ & $1.9 \pm 0.2$ & 0.66 \\
\hline Median (IQR) & $1.9(0.9-1.9)$ & $1.9(1.1-4.3)$ & \\
\hline \multicolumn{4}{|l|}{ Medicines } \\
\hline Mean \pm SD & $3.4 \pm 10.8$ & $4.3 \pm 9.5$ & 0.02 \\
\hline Median (IQR) & $0(0-57.6)$ & $0(0-96.1)$ & \\
\hline \multicolumn{4}{|c|}{ Total Service Expense } \\
\hline Mean \pm SD & $14.5+12.1$ & $13.0 \pm 9.6$ & 0.71 \\
\hline Median (IQR) & $12.0(3.8-67.7)$ & $11.9(2.1-98.0)$ & \\
\hline
\end{tabular}

*Mann-Whitney test

expenditure information for a total of 1475 sick newborns (Fig. 1).

A total of 353 sick newborns were admitted into these hospitals before free newborn care (FNC) program was implemented while 1122 sick newborns were admitted after the implementation. Sick newborns admitted in the hospital varied by various characteristics before and after the implementation of FNC program. The proportion of mothers of admitted sick newborn with basic education was higher after implementation of FNC program than before implementation ( $15.5 \%$ vs. $10.5 \%, p$ value- 0.004$)$. The proportion of mothers of admitted sick newborns from madeshi ethnic group was higher after implementation of FNC program than before implementation $(8.4 \%$ vs. $4.2 \%, p$-value-0.003). The proportion of mothers of admitted sick newborns from muslim ethnic group was higher after implementation of FNC program than before implementation $(3.4 \%$ vs. $1.7 \%, p$-value$0.03)$ The proportion of sick newborn born to multiparous mothers was lower after implementation of FNC program than before implementation ( $31.5 \%$ vs. $42.5 \%$, $p$-value-0.01) (Table 2).

We compared the duration of stay (in days) of sick newborns by neonatal morbidity before ( $\mathrm{n}-353)$ and after implementation (n-1122) of FNC. The duration of stay for babies with HIE after ( $3.3 \pm 5.9$ days) implementation of FNC was lesser than before ( $3.5 \pm 3.9$ days) implementation $(p$ value $=0.04)$. The duration of stay for babies with neonatal sepsis after $(3.7 \pm 5.9$ days $)$ implementation of FNC was lesser (4.4 \pm 4.2 days) than before implementation ( $p$ value $<0.001$ ) (Table 3$)$.

Before implementation of FNC program, $17 \%$ (60) mothers paid for sick newborn care services, while $15.3 \%$ (172) mother paid for sick newborn care after implementation. After adjusting with maternal, obstetric and neonatal characteristics, there was no change in proportion of mothers paying for sick newborn before and after implementation of FNC program after adjusting for socio-demographic characteristics (aOR-0.91, $95 \% \mathrm{CI}$, $0.65-1.28, \mathrm{p}=0.59$ ). (Table 4)

Among those who paid for the sick newborn care services (n-232), there were significant differences in the expenditure by type of service used before (n-60) and after the implementation (n-172) of the FNC program. The bed charge significantly decreased from USD $6.4 \pm 6.5$ to USD $3.1 \pm 5.3$ after implementation ( $p$-value $<0.001)$, while cost for medicine increased from Mean \pm SD USD $3.4 \pm 10.8$ to Mean \pm SD NPR $4.4 \pm 9.5$ after implementation ( $p$-value $=0.02)$. However, there was no significant difference in the OOPE (total service expenses) before (Mean \pm SD: USD 14.4+12.1) and after (Mean \pm SD: USD $13.0 \pm 9.6)$ implementation ( $p$ value $=0.71)($ Table 5$)$.

Similarly, the cost of drugs and diagnostics for sick newborns with major neonatal morbidity did not show

Table 6 Cost of care in US dollars by Neonatal morbidity

\begin{tabular}{|c|c|c|c|c|c|c|c|}
\hline \multirow{2}{*}{$\begin{array}{l}\text { Drugs and } \\
\text { Diagnostics }\end{array}$} & \multirow{2}{*}{$\begin{array}{l}N \\
(60)\end{array}$} & \multicolumn{2}{|c|}{ Before Free Newborn Care } & \multirow{2}{*}{$\begin{array}{l}\mathrm{N} \\
(172)\end{array}$} & \multicolumn{2}{|c|}{ After Free Newborn Care } & \multirow{2}{*}{$\begin{array}{l}p \text { - } \\
\text { value }\end{array}$} \\
\hline & & Mean \pm SD & Median (IQR) & & Mean \pm SD & Median (IQR) & \\
\hline$\overline{\mathrm{HIE}}$ & 7 & $3.2 \pm 2.7$ & $2.4(0-8.6)$ & 34 & $7.5 \pm 7.5$ & $6.5(0-38.4)$ & 0.10 \\
\hline NNS & 24 & $6.7 \pm 13.0$ & $2.4(0-64.4)$ & 39 & $6.1 \pm 6.2$ & $2.4(0-25.9)$ & 0.32 \\
\hline $\mathrm{HBL}$ & 6 & $2.9 \pm 1.9$ & $2.4(0-5.3)$ & 8 & $3.1 \pm 2.8$ & $2.4(0-9.6)$ & 0.89 \\
\hline MAS & 6 & $13.7 \pm 23.1$ & $4.1(0-60.0)$ & 21 & $8.1 \pm 7.5$ & $9.6(0-34.8)$ & 0.81 \\
\hline RDS & 2 & $7.9 \pm 7.8$ & $7.9(2.4-13.4)$ & 10 & $6.1 \pm 3.8$ & $6.2(0-10.0)$ & 0.66 \\
\hline Others & 15 & $4.0 \pm 4.9$ & $2.4(0-17.3)$ & 60 & $9.8 \pm 13.2$ & $7.7(0-96.0)$ & 0.007 \\
\hline
\end{tabular}


significant difference after the implementation except for that of other neonatal morbidity which increased from USD $4.0 \pm 4.9$ to USD $9.8 \pm 13.2 \quad(\mathrm{p}$-value $=0.007)$ (Table 6).

\section{Discussion}

The FNC program was implemented with the intention to overcome the burden of out of pocket expenditure on sick newborn treatment in the hospital. However, we found no significant change in the OOPE for treatment of sick newborn in the hospital before and after implementation of FNC. Though total expense among those who paid for the services received did not change significantly, there was a significant decrease in bed charge and significant increase in medicinal cost after the implementation of FNC program. This reflects that medicines may have been used not as per protocol.

Sick newborns admitted into the hospitals varied by various characteristics such as maternal education, ethnicity, parity and neonatal morbidity. After implementation of FNC, the use of sick newborn care was higher among mothers who were illiterate, literate and had basic education than before implementation. In contrast to this finding, various studies have shown that utilization of maternal and newborn care services increases with higher educational level due to higher health literacy and understanding of service utilization [27, 28].

After the implementation FNC, the proportion of sick newborns from Madhesi and Muslim ethnic groups was higher than before implementation. Also, the proportion of sick newborns admitted in the hospital from multiparous mother was higher after FNC than before implementation. This finding is similar with another study conducted in Nepal which reported that primiparous mothers have significant increment in neonatal care utilization in comparison to those of multiparous mothers[29].

Comparing the sick newborns with different neonatal morbidities, the duration of stay significantly decreased for HIE and neonatal sepsis (NNS) after the FNC program was implemented. Average duration of stay in this study significantly decreased for NNS accounting for the highest number of admissions from $4.39 \pm 4.22$ days to $3.71 \pm 5.91$ days after the implementation of FNC program. Similarly, it decreased from $3.48 \pm 3.86$ to $3.28 \pm$ 5.86 for HIE. This could be due to unavailability of medicines or diagnostics leading to an increase in the number of referrals from these public hospitals to other centers. A study conducted in Enugu, southeast Nigeria found that NNS caused the highest number of admissions, accounting for $61 \%$ of all neonatal admissions during the period under review, with a mean duration of hospital stay of $15.3 \pm 9.6$ days and a wide range of $4-50$ days. The average duration of stay in tertiary public hospitals has been reported to be higher resulting in increased cost of neonatal care[19]. The lower duration of stay in this study for sick newborns with HIE and neonatal sepsis may suggest that costs exceeded the total cost of reimbursement from the FNC program.

Similarly, the cost of drugs and diagnostics for sick newborns with major neonatal morbidity (HIE, NNS, HBL, MAS, RDS) did not show significant differences after the implementation. However, studies have reported that the cost of sick newborn care is directly proportional to type of diagnosis[19, 30]. Major neonatal morbidities like HIE and neonatal sepsis requires tailored management with varying medications for sick newborns, however, these are not reimbursed through the FNC program. The implementation of FNC program did not result in significant amount of differences in out-of-pocket expenditure for newborn care. The coverage of this package is not exhaustive to include diagnostics like PT/INR (Prothrombin Time/International Normalised Ratio), reimbursement for blood products (like packed RBC, Fresh-Frozen Plasma, Platelet-Rich Plasma and whole blood), baby diapers and surfactants for Respiratory Distress Syndrome (RDS) which has to be purchased out-of-pocket in many cases. There is a need for the evaluation of the program for better implication of the free sick newborn policy.

There are some limitations in this study. This study did not assess the expenditure for sick newborns after referral which may reflect the direct impact of FNC program. This study may be exposed to recall bias relating to the mothers' recall of expenses paid for the services received. Some information could have resulted in social desirability bias as there is a wide range in terms of expenses reported. We assume that they may have sometimes reported information based on their interpretation which is socially relevant.

\section{Conclusions}

There was no change in OOPE for sick newborns after the implementation of FNC program. The duration of hospital stays of sick newborns for various neonatal morbidities significantly decreased after the FNC program was implemented. This might imply that the OOPE per day might have increased. The cost of drugs and diagnostics in hospitals did not vary for various morbidities in sick newborns after the implementation of the FNC program. There is a need for further studies to explore the health system adequacy to implement financing strategies for free newborn care.

\section{Abbreviations}

aOR: Adjusted Odds Ratio; cOR: Crude Odds Ratio; CSPro: Census and Survey Processing System; FNC: Free Newborn Care Program; HBL: Hyperbilirubinemia; HIE: Hypoxic Ischemic Encephalopathy; IQR: Interquartile range; MAS: Meconium Aspiration Syndrome; MIS: Maternal 
Incentive Scheme; NICU: Neonatal Intensive Care Unit; NNS: Neonatal Sepsis; OOPE: Out of Pocket Expenditure; PT/INR: Prothrombin Time/International Normalised Ratio; RDS: Respiratory Distress Syndrome; SD: Standard deviation; SNCU: Specialized Newborn Care Unit; SPSS: SPSS-Statistical Package for Social Sciences; UHC: Universal Health Coverage

\section{Acknowledgements}

We would like to acknowledge Shekhar Devkota in the data cleaning Research team members and all the mothers who consented to the study. We would like to thank Nisso Nurova for reviewing the manuscript.

\section{Authors' contributions}

AKC conceptualized the study. AVS did the data-analysis and prepared the first draft of the manuscript. AA prepared the second draft of the manuscript. $O B$, PP provide input in the final data analysis and draft manuscript. MM and AKC made the final review and version of the manuscript. All authors agreed to the final manuscript.

\section{Funding}

Swedish Research Council (VR), Sweden, Laerdal Foundation for Acute Medicine, Norway and Einhorn Family Foundation, Sweden. The funders had no role in design of the study. Open Access funding provided by Uppsala University.

\section{Availability of data and materials}

The datasets used and/or analysed during the current study are available from the corresponding author on reasonable request.

\section{Ethics approval and Consent to participate}

The ethical approval for the study was taken from the Ethical Review Board (ERB) of Nepal Health Research Council (reg. no. 26-2017). Written consent was obtained from the participants enrolled in the study. Written informed consent for participation in the study was obtained where participants are children (under 16 years old) from their parent or guardian.

\section{Consent for publication}

Not applicable.

\section{Competing interests}

None.

\section{Author details}

${ }^{1}$ Golden Community, Lalitpur, Nepal. ${ }^{2}$ Ministry of Health and Population, Kathmandu, Nepal. ${ }^{3}$ Department of Women's and Children's Health, Uppsala University, Dag Hammarskjölds väg 14B, Uppsala, Sweden.

\section{Received: 24 May 2020 Accepted: 27 January 2021}

Published online: 08 February 2021

\section{References}

1. United Nations DoEaSA. United Nations Sustainable Development, Sustainable Development Goals. In. New York: United Nations; 2016.

2. World Health Organization. The World Health Report. Health System Financing: The path to Universal Coverage. In. Geneva; 2010.

3. Murray SF, Hunter BM, Bisht R, Ensor T, Bick D. Effects of demand-side financing on utilisation, experiences and outcomes of maternity care in low- and middle-income countries: a systematic review. BMC Pregnancy Childbirth. 2014;14:30.

4. Ensor T, Bhatt H, Tiwari S. Incentivizing universal safe delivery in Nepal: 10 years of experience. Health Policy Plan. 2017;32(8):1185-92.

5. Inke Mathauer E, Dale M, Jowe, Kutzin J. Purchasing health services for universal health coverage: How to make it more strategic? In. Geneva: World Health Organization; 2019.

6. Essue BM, Kimman M, Svenstrup N, Lindevig Kjoege K, Lea Laba T, Hackett ML, Jan $\mathrm{S}$. The effectiveness of interventions to reduce the household economic burden of illness and injury: a systematic review. Bull World Health Organ. 2015;93(2):102-12B.

7. Tahsina T, Ali NB, Siddique MAB, Ahmed S, Rahman M, Islam S, Rahman MM, Amena B, Hoque DME, Huda TM, et al. Determinants of hardship financing in coping with out of pocket payment for care seeking of under five children in selected rural areas of Bangladesh. PLoS One. 2018;13(5):e0196237.
8. van Doorslaer E, O'Donnell O, Rannan-Eliya RP, Somanathan A, Adhikari SR, Garg CC, Harbianto D, Herrin AN, Huq MN, Ibragimova S, et al. Catastrophic payments for health care in Asia. Health Econ. 2007;16(11):1159-84.

9. Saito E, Gilmour S, Rahman MM, Gautam GS, Shrestha PK, Shibuya K. Catastrophic household expenditure on health in Nepal: a cross-sectional survey. Bull World Health Organ. 2014;92(10):760-7.

10. World Health Organization. WHO Global Health Expenditure Atlas. In. Geneva; 2014.

11. World Health Organization. Developing a national health financing strategy. In. Geneva; 2017.

12. Engineer CY, Dale E, Agarwal A, Agarwal A, Alonge O, Edward A, Gupta S, Schuh HB, Burnham G, Peters DH. Effectiveness of a pay-for-performance intervention to improve maternal and child health services in Afghanistan: a cluster-randomized trial. Int J Epidemiol. 2016;45(2):451-9.

13. Kutzin J, Yip W, Cashin C. Alternative Financing Strategies for Universal Health Coverage. World Scientific Handbook of Global Health Economics and Public Policy 2016:267-309.

14. Hajizadeh M, Alam N, Nandi A. Social inequalities in the utilization of maternal care in Bangladesh: Have they widened or narrowed in recent years? Int J Equity Health. 2014;13:120

15. Chiranjivi Adhikari BP, Sharma, Subedi S. Out-of-Pocket and Catastrophic Expenditure of Neonatal Health Care in Kaski District, Nepal. Economic Journal of Development Issues 2018, 21.

16. Ntambue AM, Malonga FK, Cowgill KD, Dramaix-Wilmet M, Donnen P. Incidence of catastrophic expenditures linked to obstetric and neonatal care at 92 facilities in Lubumbashi, Democratic Republic of the Congo, 2015. BMC Public Health. 2019;19(1):948.

17. Srivastava NM, Awasthi S, Agarwal GG. Care-seeking behavior and out-ofpocket expenditure for sick newborns among urban poor in Lucknow, northern India: a prospective follow-up study. BMC Health Serv Res. 2009;9:61.

18. Thapa J, Budhathoki SS, Gurung R, Paudel P, Jha B, Ghimire A, Wrammert J, Kc A. Equity and Coverage in the Continuum of Reproductive, Maternal, Newborn and Child Health Services in Nepal-Projecting the Estimates on Death Averted Using the LiST Tool. Matern Child Health J. 2020;24(Suppl 1):22-30.

19. Sunny AK, Gurung R, Gurung A, Basnet O, Kc A. Out of Pocket Expenditure for Sick Newborn Care in Referral Hospitals of Nepal. Matern Child Health J. 2020;24(Suppl 1):57-65.

20. Sharma D, Murki S. Making neonatal intensive care: cost effective. J Matern Fetal Neonatal Med 2019:1-9.

21. Pannarunothai S, Mills A. The poor pay more: health-related inequality in Thailand. Soc Sci Med. 1997;44(12):1781-90.

22. Nabyonga J, Desmet M, Karamagi H, Kadama PY, Omaswa FG, Walker O. Abolition of cost-sharing is pro-poor: evidence from Uganda. Health Policy Plan. 2005;20(2):100-8.

23. Shrestha G, Paudel P, Shrestha PR, Jnawali SP, Jha D, Ojha TR, Lamichhane B. Free Newborn Care Services: A New Initiative in Nepal. J Nepal Health Res Counc. 2018;16(3):340-4.

24. Kc A, Ewald U, Basnet O, Gurung A, Pyakuryal SN, Jha BK, Bergstrom A, Eriksson L, Paudel P, Karki S, et al. Effect of a scaled-up neonatal resuscitation quality improvement package on intrapartum-related mortality in Nepal: A steppedwedge cluster randomized controlled trial. PLoS Med. 2019;16(9):e1002900.

25. Child Health Division, Department of Health Services. Ministry of Health and Population: Standard Operating Protocol for Sick Newborn Care in Health Facilities of Nepal. In. Kathmandu; 2016.

26. Child Health Division. Department of Health Services, Ministry of Health and Population: National Newborn Clinical Protocol. In. Kathmandu; 2016.

27. Tahsina T, Ali NB, Hoque DME, Huda TM, Salam SS, Hasan MM, Hossain MA, Matin Z, Kuppen L, Garnett SP, et al. Out-of-pocket expenditure for seeking health care for sick children younger than 5 years of age in Bangladesh: findings from crosssectional surveys, 2009 and 2012. J Health Popul Nutr. 2017;36(1):33.

28. Malovist $\mathrm{M}$, Pun $\mathrm{A}$, Raaijmakers $\mathrm{H}, \mathrm{Kc}$. . Persistent inequity in matemal health care utilization in Nepal despite impressive overall gains. Glob Heatth Action. 2017;10(1):1356083.

29. Sanjel K, Onta SR, Amatya A, Basel P. Patterns and determinants of essential neonatal care utilization among underprivileged ethnic groups in Midwest Nepal: a mixed method study. BMC Pregnancy Childbirth. 2019;19(1):310.

30. Narang A, Kiran PS, Kumar P. Cost of neonatal intensive care in a tertiary care center. Indian Pediatr. 2005;42(10):989-97.

\section{Publisher's Note}

Springer Nature remains neutral with regard to jurisdictional claims in published maps and institutional affiliations. 